\title{
Do campaign posters trigger voting based on looks? Probing an explanation for why good-looking candidates win more votes
}

\section{Michael Herrmann $^{1}$. Susumu Shikano ${ }^{2}$}

Published online: 11 May 2020

(c) The Author(s) 2020

\begin{abstract}
Numerous studies document that better-looking candidates win more votes. Yet the causal mechanisms leading to this advantage remain unexplored. We consider for the first time a potential trigger of the looks-vote association that has previously been suggested but not tested in the literature: exposure to campaign posters of the candidates. We test this explanation with German election survey data, which we augment with ratings - provided by MTurk workers from the U.S. - of the attractiveness and facial competence of about 1,000 district candidates. Confirming previous studies on Germany, we find that attractiveness is positively associated with candidate vote share (1.2 ppts. min-max). At the voter level, we find tentative evidence for the idea that the association is moderated by exposure to campaign posters: effects are in the expected directions and their sizes consistent with what we observe at the candidate level, but we cannot always reject the null hypothesis of no effect. In contrast to attractiveness, we do not find conclusive evidence for an effect of facial competence in the election considered. These preliminary results suggest that inundating voters with candidate posters, as in elections in Germany and many other places, might be a reason for voting based on looks.
\end{abstract}

Keywords Candidate appearance $\cdot$ Attractiveness $\cdot$ Competence $\cdot$ Campaign poster

Electronic supplementary material The online version of this article (https://doi.org/10.1057/s4126 9-020-00159-3) contains supplementary material, which is available to authorized users.

Michael Herrmann

michael.herrmann@uni-konstanz.de

Susumu Shikano

susumu.shikano@uni-konstanz.de

1 Department of Politics and Public Administration, University of Konstanz, Postfach 83, 78457 Konstanz, Germany

2 Department of Politics and Public Administration, University of Konstanz, Postfach 85, 78457 Konstanz, Germany 


\section{Introduction}

Appearance matters in elections. A plethora of studies now suggests that candidates who look more attractive, competent, or otherwise appealing win more votes. Observational evidence from numerous countries ${ }^{1}$ points to an association between looks and votes, even after controlling for various alternative explanations (Laustsen 2014; Lenz and Lawson 2011). Further experimental research established the possibility of looks to actually exert a causal influence on vote choice (Ahler et al. 2017; Budesheim and DePaola 1994). Together, these findings raise concerns about voters' abilities to make informed choices in democratic elections. In particular, while we know that voters often find themselves ill-equipped to make fully informed choices and that, instead, they rely on cues such as a candidate's party affiliation in order to reach a heuristic decision (Popkin 1991), the validity of such decisions arguably depends on how informative the employed cues are (Dancey and Sheagley 2013; Lau and Redlawsk 2001). Party affiliation, for example, might serve as a valid cue for inferring a candidate's political stances in contexts where parties are cohesive and do not alter their platforms greatly from one election to the next. However, whether the looks of a candidate provide a basis for inferring his or her political stances, or any other politically relevant qualities, is much less clear (Herrmann and Shikano 2016; Todorov et al. 2015).

Given this potentially worrying state of affairs, scholars are increasingly turning to the deeper question of what causes the observed association between looks and votes. Some argue that good-looking candidates enjoy an advantage in their relations with the media (e.g., Waismel-Manor and Tsfati 2011). In this account voters are not ultimately responsible as they do not choose candidates based on looks, but rather based on information skewed in favor of good-looking candidates. Other accounts see voters as the main causal driver (e.g., Ahler et al. 2017). As we argue below, these are important unresolved questions in research on the appearance effect in elections.

To address these questions, we need to pay closer attention to the real-world processes leading to an effect of candidate appearance in an election (either through voters or the media). In some contexts the causal mechanism may seem obvious, as, for example, when ballot papers show photographs of the candidates (Banducci et al. 2008; Buckley et al. 2007). Yet, in many other contexts for which appearance effects have been reported (among them U.S. congressional elections), no similarly obvious causal mechanism comes to mind. To truly understand the nature of the problem, who is responsible for it, and how to accommodate it, we must learn more about the mechanisms that give rise to an effect of candidate appearance in elections.

We contribute to this emerging field by testing, for the first time, whether the appearance effect originates with voters-in particular, whether exposure to campaign posters of candidates triggers voting based on looks. Our test case is German

\footnotetext{
1 Among them Australia, Brazil, Denmark, Finland, France, Germany, Ireland, Japan, Mexico, Switzerland, the UK, and the USA; for a review, see Olivola and Todorov (2010); in addition, see Laustsen (2014) and Lutz (2010).
} 
federal elections. Voters in these elections typically know very little about the candidates in their local district, which provides an opportunity for candidate appearance to affect vote choices. While ballot papers in German elections do not show pictures of the candidates, campaign posters are widely used by candidates and widespread in the weeks before an election. Previous studies document an association between the appearance and the vote share of district candidates in German parliamentary elections (Jäckle and Metz 2017; Klein and Rosar 2005; Rosar et al. 2008) and they propose candidate posters as a potential explanation for the observed association (Klein and Rosar 2005; Rosar et al. 2008). We use survey data from the 2009 election, which we augment with measures of district candidates' attractiveness and facial competence, to test this explanation. Our results indicate that attractiveness is related to vote choice among candidates that voters report having seen on posters and unrelated to vote choice among candidates that voters report not having seen.

Our findings also contribute to the cumulative body of work that estimates the size of the appearance effect in elections (see note 1). While confirming an effect of candidate attractiveness in German parliamentary elections, our estimate of the size of the effect turns out to be substantially smaller than previous ones. From a metaanalytic perspective, this suggests that the appearance effect may be more variable, and perhaps smaller, on average, than previously assumed.

\section{Sources of an appearance effect in elections}

Given abundant evidence for an effect of candidate appearance in democratic elections across the globe, more and more scholars are now turning to the deeper question of how such an effect comes about. The extant literature suggests two main explanations for the creation of an appearance effect: one in which candidate looks affect voters directly; and another in which good-looking candidates enjoy an advantage in their relations with the media, such that voters ultimately receive more, as well as more favorable information about them. We discuss both explanations in turn.

The first explanation starts from the assumption that candidate looks exert a direct influence on voting decisions. In this account voters judge candidates based on their facial appearance. A large literature in cognitive psychology shows that humans have a strong tendency for making social attributions from faces (for a review, see Todorov et al. 2015). These spontaneous judgments occur automatically and uncontrollably, within milliseconds of exposure. They are akin to what dual-process theories in psychology describe as automatic system 1 processing (Evans and Stanovich 2013), or fast thinking (Kahneman 2011), a mode of information processing that is effortless, intuitive, and typically prior to more attentive, reflective, and effortful system 2 processing. Due to their rapid and automatic nature, impressions from faces may serve as a cognitive shortcut, allowing the voter to avoid effortful system 2 processing, or they may anchor subsequent, more deliberate thinking (Todorov et al. 2005).

Perhaps the most likely scenario for such a direct effect of looks is when voters are exposed to images of the candidates in the voting booth. Scholars have 
long stressed the importance of ballot paper photographs and other voting aids ${ }^{2}$ in triggering appearance effects (Banducci et al. 2008; Buckley et al. 2007; Johns and Shephard 2011; Leigh and Susilo 2009) and evidence from these studies suggests that candidate appearance correlates strongly with votes in elections that present voters with candidate pictures on the ballot. A related possibility for candidate appearance to directly affect voters is via canvassing efforts. Studies often suggest campaign posters in the streets and on billboards, as well as leaflets, mail advertising, and newspaper ads by candidates as potential sources of an appearance effect (see, e.g., Klein and Rosar 2005; Lawson et al. 2010; Stockemer and Praino 2015). In Switzerland, for example, where voters are allowed to cast substantial numbers of preferential votes within and across party lists, voters regularly get leaflets from all the parties sent to their homes showing the candidates who are up for election in their Canton (Lutz 2010). Similarly, parties in Australia hand how-to-vote cards with candidate pictures on them to voters entering the polling place (King and Leigh 2009). Given the possibility of voters choosing candidates based on looks (Ahler et al. 2017), canvassing might trigger such decisions in elections in which voters are not exposed to candidate images in the voting booth. So far, empirical tests of such a link have been scant.

The second suggested explanation for the looks-vote association is more subtle. In this account looks exert an indirect influence on election results by shaping how politicians are treated by the media (e.g., Maurer and Schoen 2010; Tsfati et al. 2010; Waismel-Manor and Tsfati 2011). If the media treat good-looking politicians more favorably, voters who follow the news more frequently will be exposed to more favorable information about those candidates and this might affect their preferences toward them. Importantly, voters in this account do not (need to) choose candidates based on looks. The looks-vote association comes about because candidate appearance affects what information voters receive about the candidates.

One argument for such a mechanism is that reporters might prefer to cover goodlooking politicians, believing it will draw greater attention to their stories. This could be the case in televised reporting, but it may also extend to the print media (Maurer and Schoen 2010). Another argument is that reporters might be more inclined to speak to good-looking politicians, expecting them to be more charismatic and communicative interview partners. In turn, greater self-esteem and confidence might make good-looking politicians more motivated to seek news coverage (see Waismel-Manor and Tsfati 2011 for a more detailed account of these mechanisms). Apart from being selected at higher rates, good-looking politicians might also come away more positively in news reports if reporters are subject to psychological biases. In particular, a large literature demonstrates a tendency in humans to judge good-looking individuals more favorably on other unknown traits. This so-called 'halo effect' is particularly well documented for physically attractive individuals (Eagly et al. 1991) — who are perceived, among other things, as more confident, sociable, and intelligent — and it extends to judgments of politicians (Herrmann and Shikano 2016; Surawski and Ossoff 2006).

\footnotetext{
${ }^{2}$ For example, voting machines in many developing countries show pictures of the candidates as an aid for illiterate voters (Lawson et al. 2010; Moehler and Conroy-Krutz 2016).
} 
Empirical evidence for differential media treatment of good-looking politicians comes from several studies. Tsfati et al. (2010) show that physically attractive members of the Knesset appear more frequently on television, after controlling for a host of other influential factors. Waismel-Manor and Tsfati (2011) found the same relationship for U.S. members of Congress. Barrett and Barrington (2005) examine coverage of congressional and gubernatorial elections by seven Midwestern newspapers and find strong differences in how favorably candidates are portrayed on photographs. Maurer and Schoen (2010) examine articles from five local newspapers on 25 candidates at the 2005 Bundestag election. They find that attractive candidates get more as well as better press than unattractive ones. Lastly, one study also probes a link between media exposure and candidate preference. By leveraging tens of thousands of survey responses from the Cooperative Congressional Election Study in conjunction with appearance ratings of U.S. Senate and gubernatorial candidates, Lenz and Lawson (2011) show that the effect of candidate appearance on vote intention is stronger among voters who watch more television and know less about politics.

\section{The puzzle}

The possibility of media bias represents an important alternative explanation for the association between looks and votes. If good looks put candidates at an advantage in competition for voter attention, then voters who closely follow the media will potentially learn more about the positions of good-looking candidates and receive more favorable information about them. In such a lopsided informational environment, voters cannot be blamed for electing such candidates. To understand whether and to what extent the effect originates at the level of voters or the media, we need to isolate and examine more closely the different routes through which candidate appearance might translate into votes. This is not a trivial undertaking. For example, the association between TV consumption and voting based on looks reported in Lenz and Lawson (2011) is consistent with both a story of voter bias and a story of media bias in which less knowledgeable voters learn more about the views of good-looking candidates because they appear more frequently or favorably on television.

Our contribution below is to provide the first test of whether the appearance effect originates with voters. To this end we look at exposure to campaign posters, a mechanism that is often cited in the literature as a potential trigger of appearance effects (e.g., Lenz and Lawson 2011; Stockemer and Praino 2015). We examine a case in which the use of candidate posters is very widespread, making them a likely explanation for the vote-looks association. Should we find an effect of posters in this context, it would lend support to the idea that voters are influenced by candidate looks.

\section{Test case and observable implications}

We consider the effect of candidate appearance in district contests at German Bundestag elections. These contests are single-winner elections in which the seat is awarded to the candidate with the most votes. The distribution of seats in 
parliament is determined by the outcome of a second ballot - a party ballot - that voters cast independently of the candidate ballot. The outcome of the candidate ballot is usually inconsequential for the distribution of seats because district winners merely fill the seats that their party won via the second ballot. Elections in Germany are fought primarily by parties and their leaders, and the candidates that compete in local districts are not well known (Maier 2000). Most voters cannot name a single candidate in their constituency (Schmitt-Beck 1993).

The low-information character of the candidate ballot coupled with its relatively minor importance provides fertile ground for an effect of candidate appearance. Prior research indeed testifies to such an effect at the 2002 Bundestag election (Klein and Rosar 2005), the 2005 state election in North Rhine-Westphalia (Rosar, Klein and Beckers 2008), and the 2013 Bundestag election (Jäckle and Metz 2017).

Regarding potential sources of the appearance effect, by far the best chance for voters to get exposed to candidate looks is through campaign posters. According to Holtz-Bacha and Lessinger (2006: 122), in Germany "candidate posters are a classic among election posters, as they define the image of constituency-level advertising" [translation by the authors]. Posters with headshot images of district candidates are almost ubiquitous in German elections (Holtz-Bacha and Lessinger 2017; Rosar et al. 2008). They can be found on nearly every Main Street, even in small villages, weeks before the election-see the online Supporting Information (SI) for examples.

Candidate posters in Germany are also quite similar in their basic design and composition. Besides a headshot of the candidate, a typical poster shows the candidate's name and party affiliation and sometimes includes an indication of MP status or a short (party) slogan. Since candidate name, party affiliation, and MP status are also provided on ballot papers, the main takeaway from a typical poster is the candidate's face. In other words, holding all else constant, for two voters entering the voting booth, one having previously been exposed to posters while the other has not, the only systematic difference between them is that the former voter has seen some candidates' faces while the latter has not. This makes exposure to candidate posters a prime explanation for an effect of appearance. Our hypothesis, therefore, is that exposure to campaign posters moderates the effect of appearance in German elections:

Hypothesis For candidates that the voter has seen on posters, appearance has a stronger effect on vote choice than for candidates that the voter has not seen on posters.

Apart from posters, prior studies also suggest local newspapers in Germany as a potential driver of an appearance effect (Klein and Rosar 2005; Maurer and Schoen 2010). Through local newspapers, voters might get exposed to photographs of their local candidates (e.g., in articles or campaign ads). On the other hand, goodlooking candidates may enjoy greater and more positive news coverage for all the reasons outlined in the previous section, and voters may be more inclined to 
choose them on the basis of that information. Rather than being swayed by looks, voters in this scenario decide based on information whose provision is influenced by candidate appearance.

In light of these arguments, our analysis below controls for whether voters read local newspapers. We do not, however, attempt to test the media bias mechanism directly. One reason is that we do not know how widespread biased news coverage of local candidates actually is in Germany. Given the large number of local daily newspapers-over 333 in the year 2009 with an estimated 14 million subscriptions (Pasquay 2009) — it would need to be very widespread in order to affect a large number of voters. ${ }^{3}$ Moreover, even among voters who read newspapers, biased news coverage will have no effect if voters choose not to read stories about the candidates; and if a favorable news story comes up about a candidate and voters actually notice it, the story will be gone with next day's paper, thus limiting exposure time compared to candidate posters. Taken together, even if many news outlets in Germany indeed exhibit a bias toward good-looking candidates, and readers of said newspapers are indeed influenced by the more positive news coverage, the sheer number of voters to whom this would apply might be too small for the effect to show up in our voter-level analysis. By contrast, candidate posters provide a simple and direct way for candidate looks to reach voters, as posters are ubiquitous in German elections, similar in design, and voters are exposed to them up until the day of the election. Thus, if posters exhibit an effect, they potentially affect every voter. Consequently, we place greater confidence in our design's ability to detect an effect of candidate posters compared to an effect of news bias.

Lastly, recall that our goal is to understand how the appearance effect comes about. In particular, is it caused by voters or the media? Finding a correlation of looks and candidate choice among voters who read newspapers would be compatible with news bias as well as with voters being directly affected by visual coverage of the candidates. It would thus not help us answer the deeper question of what is driving the effect. While all this does not rule out the possibility of media bias contributing to the looks-vote association in Germany, we believe a different, more focused design would be necessary to uncover its actual impact.

While the prior literature on Germany mainly cites candidate posters and newspaper bias as potential sources of an appearance effect (see Klein and Rosar 2005; Maurer and Schoen 2010; Rosar et al. 2008), the broader literature discussed in the previous section suggests more ways in which an appearance effect might play out in an election. One possibility that we can rule out is exposure to ballot paper photographs, which are not permitted in German elections. Local candidates also do not appear or advertise on television. Such appearances are mostly observed by party leaders and other top-level politicians, as TV broadcasters generally cater to a national, regional, or state-wide audience. Regarding canvassing, parties in Germany

\footnotetext{
3 Note that our above count of 333 local newspapers in 2009 is conservative as many newspapers further subdivide their distribution area into smaller parts, providing local supplements with independent editorial departments for each of them. Counting all editorial departments that publish their own newspaper issue brings the count of local newspapers up to 1,511 (Pasquay 2009).
} 
do occasionally send out leaflets and other postal ads. Below, we therefore control for whether voters report having received leaflets from a local candidate. We do not attempt to test the hypothesis that looks affect voting conditional on having received such ads because, as with newspaper readership, the assumed causal chain is more fragile, and because our design is not well suited to ascertain whether leaflets indeed induce voting based on looks. ${ }^{4}$

\section{Research design}

To study the processes underlying the appearance effect, we follow Lenz and Lawson (2011) by combining appearance ratings of constituency candidates with voter survey data. Our general strategy is, first, to replicate prior findings for Germany at the candidate level by testing for an association between looks and electoral results at the 2009 Bundestag election. Having established such an association for the election in question, we then test our individual-level hypothesis about the effect being triggered by candidate posters.

\section{Data collection}

We use data from the pre- and post-election surveys $(N=2173$ and $N=2115)$ of the 2009 German Longitudinal Election Study (GLES). ${ }^{5}$ Both surveys ask if respondents have seen posters of each of the major party candidates running in their district, and whether and how often they read local or other newspapers. Our sample of district candidates is comprised of all candidates covered by the pre-election survey and consists of 1,040 candidates from 208 of Germany's 299 districts. The survey identifies the candidates of the five major parties (CDU/CSU, SPD, FDP, Greens, and The Left) in a respondent's district. Due to random sampling of respondents, the survey does not cover all districts. Table S1 in the SI shows that our candidate sample is representative of all major party candidates in 2009 with respect to key variables.

We obtained headshot photographs of the district candidates from the official webpages of the German Bundestag, state parliaments, the candidates' own

\footnotetext{
${ }^{4}$ For one thing, leaflets vary more than posters in how much additional information they provide about a candidate. This introduces measurement error and makes an effect of looks harder to identify. The effect would either have to be very large, or the sample of voters exposed to leaflets would have to be very large, or we would need to know more about what else was on the leaflet. Neither of these conditions is (likely) satisfied. Furthermore, compared to posters, which are around for weeks and difficult to avoid, voters have more control over their exposure to leaflets. This introduces the possibility that appearance might not affect vote choice directly. For example, voters might be more likely to keep leaflets of goodlooking candidates and thus be exposed to those candidates' campaign messages for a longer time. Telling apart these different causal stories requires a more focused design than the one we employ below.

5 Survey data was obtained from the GESIS archive, the study number is ZA5302.
} 
webpages, or other repositories to which the candidates submitted photographs. ${ }^{6}$ All selected pictures had to be head-and-shoulder photographs displaying the candidate against a flat or neutral background. All images were converted to black and white. For a few candidates (mostly from the socialist party The Left), we could not find suitable images. The final sample for which we obtained appearance ratings thus comprises 1,012 candidates from 208 districts. Two candidates were misclassified in the pre-election survey, which brings the number of candidates used in the analysis to 1,010 .

We collected ratings of physical attractiveness and facial competence of all candidates. Prior studies on the appearance effect in elections have mostly focused on one of these two characteristics (e.g., Banducci et al. 2008; King and Leigh 2009; Lenz and Lawson 2011; Todorov et al. 2005) or both (e.g., Berggren et al. 2010; Laustsen 2014; Lutz 2010; Olivola and Todorov 2010; Praino et al. 2014). Most prior work on German elections focuses on attractiveness (Klein and Rosar 2005; Maurer and Schoen 2010; Rosar et al. 2008) but it seems reasonable to assume that facial competence might also affect voting decisions in Germany (Jäckle and Metz 2017).

We follow earlier work in having photographs judged by raters from another country (Antonakis and Dalgas 2009; Berggren et al. 2010; King and Leigh 2009; Lawson et al. 2010; Praino and Stockemer 2019; Praino et al. 2014; Rule et al. 2010; Stockemer and Praino 2017). Specifically, ratings were provided by Amazon Mechanical Turk (MTurk) workers from the U.S. Ratings by outsiders make for a cleaner and unbiased measurement of the desired traits (see Lawson et al. 2010 for a discussion). They also allow us to rule out the possibility that raters might, consciously or unconsciously, recognize any of the candidates or that their judgments get tainted by stereotypes about German politicians' appearance (Berggren et al. 2010). Unlike student raters, who are well educated and mostly under age 30, workers on MTurk span a much larger age range and include people from different educational backgrounds (Berinsky et al. 2012; Huff and Tingley 2015). Such diversity should make ratings from MTurk workers more representative of views held in the general population than those of student raters. A detailed description of the data collection process along with statistics on workers and appearance ratings is provided in the SI.

Each worker rated a batch of 50 pictures, which were presented one at a time and in random order. ${ }^{7}$ The worker rated either the attractiveness or the competence of the displayed person, but not both, on a 7-point scale. The payment for this 'human intelligence task' (HIT) was 1 dollar and the average time to completion was about $6 \mathrm{~min}$. Each rater was allowed to participate for at most two times: once to provide attractiveness ratings and once to provide competence ratings for batches of 50 pictures each. Ratings of attractiveness and competence were collected two months

\footnotetext{
${ }^{6}$ Note that the webpages of the Bundestag and other assemblies provide us with footage on successful as well as many unsuccessful district candidates. This is because most candidates who are unsuccessful in the district nevertheless get elected due to their placement on the party list. In other instances, candidates who do not win a Bundestag mandate were, or later became, members of state parliaments and other lower-level assemblies. Images were collected in spring 2013. For pictures taken after the election.

7 There were a total of 21 batches for each rating task. Two of these batches contained only 31 pictures because our sample comprised 1,012 political candidates.
} 
apart. Hence, no rater provided more than 50 attractiveness and 50 competence ratings, and no rater simultaneously judged both traits for the same candidates.

Each batch of pictures was judged by 28 raters, on average. Reliability of attractiveness ratings was very high (Cronbach's alpha: $\min =0.93, \max =0.97$, mean $=0.95$ ). Competence ratings, by contrast, were less reliable (Cronbach's alpha: $\min =0.79$, $\max =0.95$, mean $=0.87$; see Table S4 in the SI). Following standard practice, we obtained attractiveness and facial competence scores for each image by averaging all its ratings. Overall, the candidates in our sample score higher and vary less in facial competence $($ mean $=4.4, \mathrm{SD}=0.6$ ) than in attractiveness (mean $=3.3$, $\mathrm{SD}=0.8$; see Figure S2 and Table S5 in the SI). In line with previous studies (e.g., Lutz 2010; Olivola and Todorov 2010), we found attractiveness and facial competence ratings to be moderately correlated $(r=0.45)$.

\section{Identifying the effect of candidate looks}

Since voters can only choose among the candidates in their respective district, an effect of looks implies that better-looking candidates should win more votes relative to their competitors in the district, and the size of this effect should be proportional to the size of the appearance advantage: if all candidates in the constituency are good looking, the effect on vote choice should be small; if one candidate stands out from the rest, the effect on vote share should be large (a 'frog pond' effect; see Rosar et al. 2008). Consequently, we choose a statistical approach that identifies the effect of looks by comparing only those candidates that a voter actually faces, that is: we do not compare candidates from different districts (for similar strategies, see Antonakis and Dalgas 2009; Berggren et al. 2010; Lutz 2010; Praino and Stockemer 2019; Praino et al. 2014; Todorov et al. 2005).

At the level of candidates, we employ linear regression with district fixed effects to achieve this. Fixed-effects estimation identifies the effect of candidate appearance on vote share by using deviations of both variables from their respective district means (Cameron and Trivedi 2005, pp. 702-703, 726). ${ }^{8}$ Mean differencing erases any between-district variation in the overall levels of both variables. In effect, the regression coefficients are estimated solely from within-district variation. Thus, the better a candidate looks compared to the average in the district, the larger his or her share of the vote should be compared to the average in the district. At the level of the individual voter, we infer the effect of looks via conditional logit analysis of candidate choice. This approach mirrors our identification strategy at the candidate level by comparing only those candidates with each other that a voter actually faces, i.e., the candidates that compete in his or her district. In doing so, conditional logit also

\footnotetext{
${ }^{8}$ For two-candidate races, the fixed effects approach is essentially the same as regressing the vote margin on the difference in candidate attributes (e.g., Antonakis and Dalgas 2009; Praino and Stockemer 2019; Todorov et al. 2005). For multicandidate elections, Berggren, Jordahl and Poutvaara (2010) use a fixed effects approach in order to compare candidates from the same party list in terms of their share of preference votes.
} 
considers only differences in the attributes of alternatives, not their absolute values (Train 2009, pp. 19-20).

\section{Control variables}

To rule out spurious correlation, we control for a large set of factors that might plausibly influence candidate vote share in German elections (see Herrmann and Tepe 2018). The first factor is the candidate's party. At the voter level we control for party via standard measures of party preference (i.e., feeling thermometers as well as party identification). In the candidate-level analyses, we control for the strength of a candidate's party by including its share of second votes in the district. In addition, we include party dummies in both kinds of analyses to account for the fact that some parties (in particular the CDU and SPD) tend to win more first votes than second votes, while other parties tend to win fewer first votes, and we include one such set of party dummies for East Germany and one for West Germany to account for known regional differences in split-ticket voting.

Second, we control for candidate strength, in particular seniority and political experience, by including incumbency status and MP status. The latter measure also covers constituency candidates who previously obtained a seat through their party list. We also control for 'double nominations' that is, whether a constituency candidate also runs on the party list. Lastly, we include a dummy for candidates that are well known to the public due to their elevated position in the party or parliamentary hierarchy, in particular cabinet ministers, floor leaders, and party leaders (see Table S8 in the SI for their identities).

Third, we control for candidate gender and (log of) age to avoid misattributing age and gender differences to candidate appearance, and we include controls for other candidate attributes that are known to voters because they get printed on the ballot paper. ' These include academic titles, in particular 'Dr.' and 'Prof.', and candidate occupation, which was coded into standard occupational prestige categories (Blossfeld et al. 2001).

A breakdown of candidates' average attractiveness and facial competence scores by gender, party, and other characteristics (see Tables S6 and S7 in the SI) reveals that appearance is indeed related to these covariates: female candidates are perceived as more attractive and more competent looking, on average; candidates from conservative parties (CDU, CSU, and FDP) are perceived as more competent looking, regardless of gender; district incumbents of the two strongest parties (CDU/ CSU, and SPD) are perceived as more attractive and more competent looking than non-incumbents, regardless of gender; and MPs are perceived as more competent looking than non-MPs, regardless of gender and party.

In addition to candidate characteristics and party support, our voter-level analysis further includes a set of controls related to the likelihood of (self-reported) exposure to campaign posters. For one, we adjust for potential differences in the likelihood of

\footnotetext{
9 These data as well as information on vote share and other candidate characteristics were provided by the federal returning officer (Bundeswahlleiter).
} 
exposure due to district geography. We use (log) population density as a measure, since exposure to candidate posters is arguably more likely in densely populated, urban districts. Second, we control for voter attentiveness to politics by including a standard measure of political interest (5-point scale). Third, we control for voter sophistication by including a measure of political system knowledge. The measure counts the number of correct answers to two questions about the workings of the German electoral system. The survey did not include any other political knowledge items.

Lastly, our voter-level analysis controls for ways in which voters might get exposed to information about the candidates in their district other than through posters. In particular, we control for self-reported local newspaper readership, whether voters report having received a leaflet from a candidate, and whether they report having come into direct contact with a candidate.

\section{Results}

\section{Is there an effect of candidate appearance on electoral success?}

From Table 1 we see that attractiveness has a significant effect of 0.26 percentage points on candidate vote share (see Table S9 in the SI for the complete regression results). Candidate attractiveness in our sample ranges from about 1.4 to 6 points. Thus, holding all else constant, we would expect the most and least attractive-looking candidates to differ by about 1.2 percentage points. This is less than what previous studies have found: about $37 \%$ the size of the effects reported in Klein and Rosar (2005), about 50\% the size of the effects reported in Rosar et al. (2008), and about $65 \%$ the size of the effect reported in Jäckle and Metz (2017).

Facial competence is also positively associated with elections results, but the effect is smaller $(0.2$ ppts. resp. 0.78 ppts. for a min-max change in observed facial competence) and more uncertain, thus failing to reach statistical significance. Including both attractiveness and facial competence in the model reduces the effect of facial competence to zero, while the effect of attractiveness retains its size. The finding that attractiveness is a stronger predictor of electoral results than facial competence is in line with findings in Berggren et al. (2010), Jäckle and Metz (2017), Lutz (2010), Mattes and Milazzo (2014), and Praino et al. (2014).

\section{Does exposure to candidate posters moderate the effect of appearance?}

Table 2 shows that attractiveness has a positive effect on vote choice for candidates that the voter reports having seen on posters; for candidates that voters have not seen on posters, the effect is essentially zero (see Table S10 in the SI for full results). The model in column 1 most closely mirrors the candidate-level model by controlling for candidate characteristics and party support. Column 2 adds further controls for the likelihood of exposure to candidate posters (i.e., population density, voter interest in politics, and political knowledge). Column 3 adds controls for other ways in 
Table 1 The effect of looks on candidate vote share

\begin{tabular}{|c|c|c|c|}
\hline & (1) & (2) & (3) \\
\hline Cand. attractiveness & $\begin{array}{l}0.26^{*} \\
(0.12)\end{array}$ & & $\begin{array}{l}0.24^{+} \\
(0.13)\end{array}$ \\
\hline Cand. facial competence & & $\begin{array}{l}0.20 \\
(0.14)\end{array}$ & $\begin{array}{l}0.04 \\
(0.16)\end{array}$ \\
\hline District incumbent & $\begin{array}{l}3.12^{* * * *} \\
(0.34)\end{array}$ & $\begin{array}{l}3.16^{* * * *} \\
(0.33)\end{array}$ & $\begin{array}{l}3.13 * * * \\
(0.34)\end{array}$ \\
\hline Top leading politician & $\begin{array}{l}2.85^{* *} \\
(0.96)\end{array}$ & $\begin{array}{l}2.87 * * \\
(0.95)\end{array}$ & $\begin{array}{l}2.86^{* *} \\
(0.96)\end{array}$ \\
\hline MP & $\begin{array}{l}1.04 * * * \\
(0.22)\end{array}$ & $\begin{array}{l}1.03^{* * * *} \\
(0.22)\end{array}$ & $\begin{array}{l}1.04 * * * \\
(0.22)\end{array}$ \\
\hline Academic title: $\mathrm{Dr}$ & $\begin{array}{l}0.45^{*} \\
(0.22)\end{array}$ & $\begin{array}{l}0.45^{*} \\
(0.22)\end{array}$ & $\begin{array}{l}0.45^{*} \\
(0.22)\end{array}$ \\
\hline Academic title: Prof & $\begin{array}{l}1.55^{* *} \\
(0.58)\end{array}$ & $\begin{array}{l}1.46^{*} \\
(0.57)\end{array}$ & $\begin{array}{l}1.54 * * \\
(0.58)\end{array}$ \\
\hline Female cand & $\begin{array}{l}-0.24 \\
(0.18)\end{array}$ & $\begin{array}{l}-0.13 \\
(0.18)\end{array}$ & $\begin{array}{l}-0.24 \\
(0.19)\end{array}$ \\
\hline Cand. age (log) & $\begin{array}{l}0.66^{+} \\
(0.38)\end{array}$ & $\begin{array}{l}0.19 \\
(0.41)\end{array}$ & $\begin{array}{l}0.62 \\
(0.44)\end{array}$ \\
\hline Share of 2 nd votes & $\begin{array}{l}1.03^{* * *} \\
(0.02)\end{array}$ & $\begin{array}{l}1.03 * * * \\
(0.02)\end{array}$ & $\begin{array}{l}1.03 * * * \\
(0.02)\end{array}$ \\
\hline Further controls (not shown) & Yes & Yes & Yes \\
\hline Constituency fixed effects & Yes & Yes & Yes \\
\hline Party fixed effects by region & Yes & Yes & Yes \\
\hline Observations & 1010 & 1010 & 1010 \\
\hline Districts & 208 & 208 & 208 \\
\hline
\end{tabular}

Robust standard errors (clustered by constituency) in parentheses ${ }^{+} p<0.1, * p<0.05, * * p<0.01, * * * p<0.001$

which voters might get informed about the candidates (i.e., local newspaper readership, exposure to candidate leaflets, and direct contact with candidate). Across all three specifications, the effects of attractiveness remain substantively the same, and significantly different from zero (marginally in model 3), conditional on seeing posters. In all three models the difference between the two effects of attractiveness (i.e., conditional on having seen posters vs. not having seen posters) is not statistically significant.

Apart from statistical significance, the effect sizes shown in Table 2 are also consistent with what we found at the candidate level. The left panel of Fig. 1 illustrates the effects of candidate attractiveness on the (average) probability of voting for a candidate, conditional on seeing posters of the candidate. ${ }^{10}$ Since the predicted

\footnotetext{
10 Probabilities were computed using the observed value approach (Hanmer and Ozan Kalkan 2013). Computations were performed with the "predictnl" routine of Stata 15, see the SI for details.
} 
Table 2 Exposure to candidate posters and attractiveness' effect on candidate choice

\begin{tabular}{llll}
\hline & $(1)$ & $(2)$ & $(3)$ \\
\hline Seen cand. poster*Cand. attractiveness & $0.17^{*}$ & $0.16^{*}$ & $0.14^{+}$ \\
Not seen cand. poster*Cand. attractiveness & $(0.08)$ & $(0.08)$ & $(0.08)$ \\
& 0.02 & 0.03 & 0.03 \\
Seen cand. poster & $(0.08)$ & $(0.08)$ & $(0.08)$ \\
& -0.23 & -0.18 & -0.12 \\
Voter party rating & $(0.35)$ & $(0.35)$ & $(0.35)$ \\
& $0.80^{* * *}$ & $0.80^{* * *}$ & $0.81^{* * *}$ \\
Voter party identification & $(0.03)$ & $(0.03)$ & $(0.03)$ \\
& $1.53^{* * *}$ & $1.55^{* * *}$ & $1.53^{* * *}$ \\
Constants for each party by region & $(0.08)$ & $(0.08)$ & $(0.08)$ \\
Other candidate characteristics & Yes & Yes & Yes \\
Likelihood of exposure to posters & Yes & Yes & Yes \\
Other potential sources of information about candidates & & Yes & Yes \\
Observations & 13,641 & 13,623 & 13,613 \\
Respondents & 2820 & 2816 & 2814 \\
\hline
\end{tabular}

Standard errors in parentheses

${ }^{+} p<0.1, * p<0.05, * * p<0.01, * * * p<0.001$
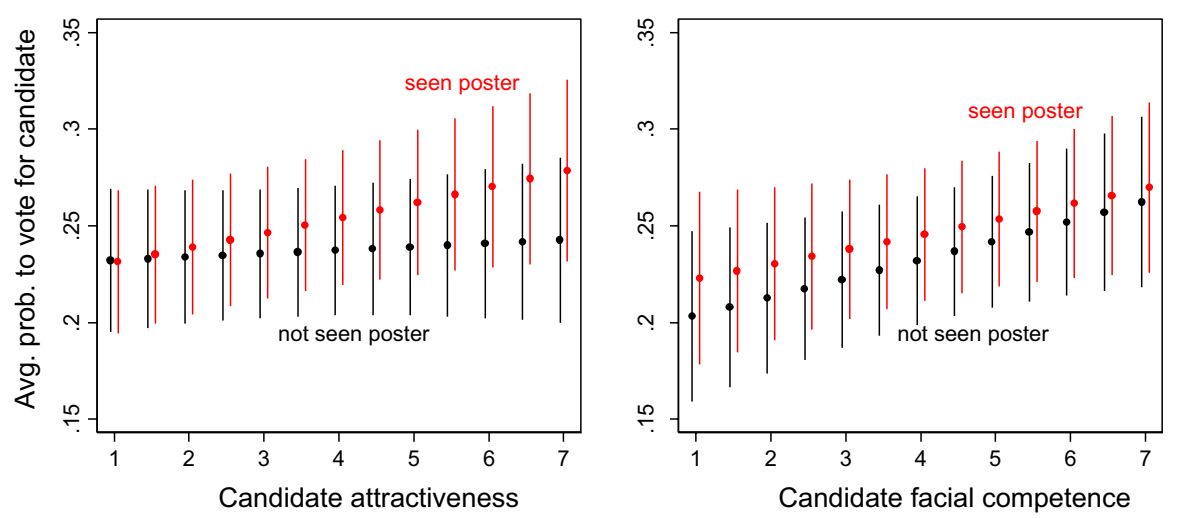

Fig. 1 The effects of candidate attractiveness and facial competence on voters who have seen posters of the candidate or not. Calculations based on column 3 of Tables 2 and 3, respectively. The graphs show the average probability of voting for a candidate and associated $90 \%$ confidence intervals, while holding all other variables at their observed values

relationship is almost linear, a one-unit increase in attractiveness on the 7-point scale is roughly associated with an increase in the average probability of voting for the candidate by about 0.67 percentage points ( 4.7 ppts. divided by 7 ), holding all other variables at their observed values. As about 40 percent of voters in our sample report having seen posters of the candidates, increasing attractiveness by one unit 
Table 3 Exposure to candidate posters and facial competence's effect on candidate choice

\begin{tabular}{llll}
\hline & $(1)$ & $(2)$ & $(3)$ \\
\hline Seen cand. poster*Cand. facial competence & 0.14 & 0.15 & 0.15 \\
Not seen cand. poster*Cand. facial competence & $(0.10)$ & $(0.10)$ & $(0.10)$ \\
Seen cand. poster & $0.18^{+}$ & $0.18^{+}$ & $0.19^{+}$ \\
& $(0.11)$ & $(0.11)$ & $(0.11)$ \\
Voter party rating & 0.42 & 0.40 & 0.44 \\
Voter party identification & $(0.60)$ & $(0.60)$ & $(0.61)$ \\
& $0.80^{* * *}$ & $0.80^{* * *}$ & $0.80^{* * *}$ \\
Constants for each party by region & $(0.03)$ & $(0.03)$ & $(0.03)$ \\
Other candidate characteristics & $1.53^{* * *}$ & $1.55^{* * *}$ & $1.53^{* * *}$ \\
Likelihood of exposure to posters & $(0.08)$ & $(0.08)$ & $(0.08)$ \\
Other potential sources of information about candidates & Yes & Yes & Yes \\
Observations & Yes & Yes & Yes \\
Respondents & 13,641 & Yes & Yes \\
\hline
\end{tabular}

Standard errors in parentheses

$+p<0.1, * p<0.05, * * p<0.01, * * * p<0.001$

thus translates into an estimated $0.26(0.67 \times 0.4)$ ppts-increase in votes, on average. This is the same effect size that we estimated at the candidate level.

For facial competence, we find no evidence for an effect of campaign posters. Across all three model specifications in Table 2 the coefficients of facial competence are positive and about the same size, regardless of whether voters have seen posters of the candidates or not (see Table S11 in the SI for full results). The lack of moderation is also visible in Fig. 1, right panel. Furthermore, contrary to expectation, the effects of facial competence that reach statistical significance are those for candidates that voters report not having seen on posters. The difference between the conditional effects of facial competence is also not statistically significant in any of the models. ${ }^{11}$

\section{Discussion}

Our results support a story in which attractive-looking candidates enjoy a small bonus among voters who have seen them on campaign posters. In line with previous studies showing an attractiveness bonus at German parliamentary elections, we find that attractive-looking candidates enjoy an electoral advantage (Jäckle and Metz

\footnotetext{
11 We also re-ran all our analyses excluding top leading politicians entirely from the sample. The results of these additional analyses, which are similar to the ones reported above, can be found in Tables S12 to S13 in the SI.
} 
2017; Klein and Rosar 2005; Rosar et al. 2008). At the voter level, we find tentative support for the hypothesis that the observed association is due to campaign posters of the candidates. First, the effect of candidate attractiveness is positive and (mostly) statistically significant for candidates that voters have seen on posters. Second, its size is consistent with what we observe at the candidate level. Third, we find no significant effect of attractiveness on the choice of candidates that voters have not seen on posters. However, we cannot reject the null hypothesis of no difference between the two effects.

Our results are inconclusive regarding an effect of candidate facial competence. For one thing, facial competence produces only a small and statistically insignificant effect at the candidate level. While the effect is not much smaller than that of attractiveness, it does go to zero when attractiveness is included in the model. The effect of attractiveness, on the other hand, retains its size when facial competence is controlled for. Prior research has repeatedly documented an effect of attractiveness in German parliamentary elections (Jäckle and Metz 2017; Klein and Rosar 2005; Rosar et al. 2008). To date there is only one study showing an effect of facial competence (Jäckle and Metz 2017). The effect of competence in that study turned out not to be robust to the inclusion of control variables - in particular district incumbency. At the voter level, we find facial competence to be positively associated with voting for a candidate, regardless of whether the candidate was seen on posters or not and most strongly for candidates that voters report not having seen on posters. This defies expectations held widely in the literature that exposure to posters triggers appearance effects.

One reason for this lack of clarity could be measurement error. Ratings of facial competence in our study were less reliable than ratings of attractiveness. Since measurement error in predictor variables can lead to increased variation in estimated effect sizes (Loken and Gelman 2017) —especially in small to medium-sized samples - this might explain why our findings were more mixed with regard to facial competence (note the larger standard errors on facial competence's effects across all models). Another explanation might be that U.S. raters judge facial competence differently from Germans. However, recent studies have shown that raters from Asian countries generally agree with U.S. raters in their assessments of politicians' facial competence and their assessments are equally predictive of those politicians' electoral success ( $\mathrm{Na}$ et al. 2015; Rule et al. 2011). Further research will be needed to determine whether facial competence exerts an effect at Bundestag elections and if so, how. Our results at this point do not add much beyond the current state of research.

\section{Conclusion}

Our study is the first to test a widespread assumption that inundating voters with facial photographs of candidates around election time can lead to voting based on looks (e.g., Lawson et al. 2010). Conditional on seeing posters, we estimate the effect of candidate attractiveness on the probability of voting at about 4.7 percentage points, for a minimum-to-maximum change in observed attractiveness. For some 
readers this might seem too small given the ubiquity of campaign posters in German elections and given German voters' lack of familiarity with their local district candidates, both of which should make them more susceptible to candidate looks. One should bear in mind, though, that German elections are, first and foremost, fought by parties and party leaders. Most voters choose district candidates based on their party affiliation, not looks, a fact that is also evident from the strong effects of party in each of our analyses. In contexts where party allegiances are weaker, as, for example, in many post-communist countries or developing countries, exposure to candidate posters might well lead to larger appearance effects than those reported here-as long as voters do not have other reasons (e.g., gender or ethnicity) to vote for a candidate.

We also found the effects of appearance on election results to be substantially smaller than those reported in previous studies (Jäckle and Metz 2017; Klein and Rosar 2005; Rosar et al. 2008). Roughly, the effect sizes in our study are about half of what previous studies have found. This suggests that the effect of appearance might be more variable (from election to election) and perhaps also smaller, on average, than previously assumed.

Given the small effects that we found and the lack of statistical significance in some of the relevant comparisons, more research will be necessary to ascertain the role of campaign posters in moderating the effect of candidate looks on voting. If our current results hold up, they imply a limit on efforts to reduce the effect of looks. In particular they suggest that removing candidate photographs from ballot papers, which many previous studies identify as a major source for appearance effects (Banducci et al. 2008; Buckley et al. 2007; Johns and Shephard 2011; Lawson et al. 2010), might not help purge elections from the influence of candidate appearance if the candidates are allowed to fill streets with their portraits. Unless the usage of facial photographs in electoral advertising is severely curbed-and it is not clear that such a move would be desirable - the vote-looks association is likely to persist.

Acknowledgements Open Access funding provided by Projekt DEAL. We thank panellists at the 2015 MPSA Annual Conference for their feedback on an earlier version of this paper. We are grateful to Tobias Stark for his support in collecting appearance ratings via MTurk. Daniel Höhmann and Steffen Zabler provided research assistance. This research was supported by the University of Konstanz with funds from the Excellence Initiative of the German federal and state governments.

\section{Compliance with ethical standards}

Conflict of interest On behalf of all authors, the corresponding author states that there is no conflict of interest.

Open Access This article is licensed under a Creative Commons Attribution 4.0 International License, which permits use, sharing, adaptation, distribution and reproduction in any medium or format, as long as you give appropriate credit to the original author(s) and the source, provide a link to the Creative Commons licence, and indicate if changes were made. The images or other third party material in this article are included in the article's Creative Commons licence, unless indicated otherwise in a credit line to the material. If material is not included in the article's Creative Commons licence and your intended use is not permitted by statutory regulation or exceeds the permitted use, you will need to obtain permission directly from the copyright holder. To view a copy of this licence, visit http://creativecommons.org/licen ses/by/4.0/. 


\section{References}

Ahler, D.J., J. Citrin, M.C. Dougal, and G.S. Lenz. 2017. Face Value? Experimental Evidence that Candidate Appearance Influences Electoral Choice. Political Behavior 39 (1): 77-102.

Antonakis, J., and O. Dalgas. 2009. Predicting Elections: Child's Play! Science 323 (5918): 1183.

Banducci, S.A., A.K. Jeffrey, M. Thrasher, and C. Rallings. 2008. Ballot Photographs as Cues in LowInformation Elections. Political Psychology 29 (6): 903-917.

Barrett, A.W., and L.W. Barrington. 2005. Bias in Newspaper Photograph Selection. Political Research Quarterly 58 (4): 609-618.

Berggren, N., H. Jordahl, and P. Poutvaara. 2010. The Looks of a Winner: Beauty and Electoral Success. Journal of Public Economics 94 (1-2): 8-15.

Berinsky, A.J., G.A. Huber, and G.S. Lenz. 2012. Evaluating Online Labor Markets for Experimental Research: Amazon.com's Mechanical Turk. Political Analysis 20 (03): 351-368.

Blossfeld, H.-P., Drobnic, S., \& Rohwer, G. (2001). Spouses' Employment Careers in (West) Germany. Careers of Couples in Contemporary Societies, 53-76.

Buckley, F., N. Collins, and T. Reidy. 2007. Ballot Paper Photographs and Low-Information Elections in Ireland. Politics 27 (3): 174-181.

Budesheim, T.L., and S.J. DePaola. 1994. Beauty or the Beast? The Effects of Appearance, Personality, and Issue Information on Evaluations of Political Candidates. Personality and Social Psychology Bulletin 20 (4): 339-348.

Cameron, A.C., and P.K. Trivedi. 2005. Microeconometrics: Methods and Applications. Cambridge: Cambridge University Press.

Dancey, L., and G. Sheagley. 2013. Heuristics Behaving Badly: Party Cues and Voter Knowledge. American Journal of Political Science 57 (2): 312-325.

Eagly, A.H., R.D. Ashmore, M.G. Makhijani, and L.C. Longo. 1991. What is Beautiful is Good, But...: A Meta-Analytic Review of Research on the Physical Attractiveness Stereotype. Psychological Bulletin 110 (1): 109-128.

Evans, J.S.B.T., and K.E. Stanovich. 2013. Dual-Process Theories of Higher Cognition: Advancing the Debate. Perspectives on Psychological Science 8 (3): 223-241.

Hanmer, M.J., and K. Ozan Kalkan. 2013. Behind the Curve: Clarifying the Best Approach to Calculating Predicted Probabilities and Marginal Effects from Limited Dependent Variable Models. American Journal of Political Science 57 (1): 263-277.

Herrmann, M., and S. Shikano. 2016. Attractiveness and Facial Competence Bias Face-Based Inferences of Candidate Ideology. Political Psychology 37 (3): 401-417.

Herrmann, M., and M. Tepe. 2018. Does Exposure to Stereotype-Disconfirming Politicians Reduce the Effect of Stereotypes on Voting? Evidence from Seven Plagiarism Scandals in Germany. Political Psychology 39 (2): 303-324.

Holtz-Bacha, C., and E.-M. Lessinger. 2006. Politische Farbenlehre: Plakatwahlkampf 2005. In Die Massenmedien im Wahlkampf, ed. C. Holtz-Bacha, 80-125. Wiesbaden: VS Verlag für Sozialwissenschaften.

Holtz-Bacha, C., and E.-M. Lessinger. 2017. Indispensable and very much alive: Posters in German election campaigns. In Election Posters Around the Globe: Political Campaigning in the Public Space, ed. C. Holtz-Bacha and B. Johansson, 159-186. Cham, Cham: Springer International Publishing.

Huff, C., and D. Tingley. 2015. "Who are These People?": Evaluating the Demographic Characteristics and Political Preferences of MTurk Survey Respondents. Research \& Politics 2 (3): 1-12.

Jäckle, S., and T. Metz. 2017. Beauty Contest Revisited: The Effects of Perceived Attractiveness, Competence, and Likability on the Electoral Success of German MPs. Politics \& Policy 45 (4): 495-534.

Johns, R., and M. Shephard. 2011. Facing the Voters: The Potential Impact of Ballot Paper Photographs in British Elections. Political Studies 59 (3): 636-658.

Kahneman, D. 2011. Thinking, Fast and Slow. New York: Penguin Books.

King, A., and A. Leigh. 2009. Beautiful Politicians. Kyklos 62 (4): 579-593.

Klein, M., and U. Rosar. 2005. Physische Attraktivität und Wahlerfolg Eine empirische Analyse am Beispiel der Wahlkreiskandidaten bei der Bundestagswahl 2002. Politische Vierteljahresschrift 46 (2): 263-287. 
Lau, R.R., and D.P. Redlawsk. 2001. Advantages and Disadvantages of Cognitive Heuristics in Political Decision Making. American Journal of Political Science. https://doi.org/10.2307/2669334.

Laustsen, L. 2014. Decomposing the Relationship Between Candidates' Facial Appearance and Electoral Success. Political Behavior 36 (4): 777-791.

Lawson, C., G.S. Lenz, A. Baker, and M. Myers. 2010. Looking Like a Winner: Candidate Appearance and Electoral Success in New Democracies. World Politics 62 (4): 561-593.

Leigh, A., and T. Susilo. 2009. Is Voting Skin-Deep?: Estimating the Effect of Candidate Ballot Photographs on Election Outcomes. Journal of Economic Psychology 30 (1): 61-70.

Lenz, G.S., and C. Lawson. 2011. Looking the Part: Television Leads Less Informed Citizens to Vote Based on Candidates' Appearance. American Journal of Political Science 55 (3): 574-589.

Loken, E., and A. Gelman. 2017. Measurement Error and the Replication Crisis. Science 355 (6325): 584-585.

Lutz, G. 2010. The Electoral Success of Beauties and Beasts. Swiss Political Science Review 16 (3): $457-480$.

Maier, J. 2000. Politisches Interesse und politisches Wissen in Ost- und Westdeutschland. In Wirklich ein Volk?, ed. J.W. Falter, O.W. Gabriel, and H. Rattinger, 141-171. Wiesbaden: VS Verlag für Sozialwissenschaften.

Mattes, K., and C. Milazzo. 2014. Pretty Faces, Marginal Races: Predicting Election Outcomes Using Trait Assessments of British Parliamentary Candidates. Electoral Studies 34: 177-189.

Maurer, M., and H. Schoen. 2010. Der mediale Attraktivitätsbonus: Wie die physische Attraktivität von Wahlkreiskandidaten die Medienberichterstattung in Wahlkämpfen beeinflusst. KZfSS Kölner Zeitschrift für Soziologie und Sozialpsychologie 62 (2): 277-295.

Moehler, D., and J. Conroy-Krutz. 2016. Eyes on the Ballot: Priming Effects and Ethnic Voting in the Developing World. Electoral Studies 42: 99-113.

Na, J., S. Kim, H. Oh, I. Choi, and A. O'Toole. 2015. Competence Judgments Based on Facial Appearance Are Better Predictors of American Elections Than of Korean Elections. Psychological science 26 (7): 1107-1113.

Olivola, C.Y., and A. Todorov. 2010. Elected in 100 Milliseconds: Appearance-Based Trait Inferences and Voting. Journal of Nonverbal Behavior 34 (2): 83-110.

Pasquay, A. 2009. Die deutschen Zeitungen in Zahlen und Daten. Berlin: Bundesverband Deutscher Zeitungsverleger (BDZV).

Popkin, S.L. 1991. The Reasoning Voter: Communication and Persuasion in Presidential Campaigns. Chicago, London: University of Chicago Press.

Praino, R., and D. Stockemer. 2019. What are Good-Looking Candidates, and can They Sway Election Results? Social Science Quarterly 100 (3): 531-543.

Praino, R., D. Stockemer, and J. Ratis. 2014. Looking Good or Looking Competent? Physical Appearance and Electoral Success in the 2008 Congressional Elections. American Politics Research 42 (6): 1096-1117.

Rosar, U., M. Klein, and T. Beckers. 2008. The Frog Pond Beauty Contest: Physical Attractiveness and Electoral Success of the Constituency Candidates at the North Rhine-Westphalia State Election of 2005. European Journal of political Research 47 (1): 64-79.

Rule, N.O., N. Ambady, R.B. Adams, H. Ozono, S. Nakashima, S. Yoshikawa, et al. 2010. Polling the Face: Prediction and Consensus Across Cultures. Journal of Personality and Social Psychology 98 (1): 1-15.

Rule, N.O., K. Ishii, and N. Ambady. 2011. Cross-Cultural Impressions of Leaders' Faces: Consensus and Predictive Validity. International Journal of Intercultural Relations 35 (6): 833-841.

Schmitt-Beck, R. 1993. Denn sie wissen nicht, was sie tun... Zum Verständnis des Verfahrens der Bundestagswahl bei westdeutschen und ostdeutschen Wählern. Zeitschrift für Parlamentsfragen 24 (3): 393-415.

Stockemer, D., and R. Praino. 2015. Blinded by Beauty? Physical Attractiveness and Candidate Selection in the U.S. House of Representatives. Social Science Quarterly 96 (2): 430-443.

Stockemer, D., and R. Praino. 2017. Physical Attractiveness, Voter Heuristics and Electoral Systems: The Role of Candidate Attractiveness Under Different Institutional Designs. The British Journal of Politics and International Relations 19 (2): 336-352.

Surawski, M.K., and E.P. Ossoff. 2006. The Effects of Physical and Vocal Attractiveness on Impression Formation of Politicians. Current Psychology 25 (1): 15-27.

Todorov, A., A.N. Mandisodza, A. Goren, and C.C. Hall. 2005. Inferences of Competence from Faces Predict Election Outcomes. Science 308 (5728): 1623-1626. 
Todorov, A., C.Y. Olivola, R. Dotsch, and P. Mende-Siedlecki. 2015. Social Attributions from Faces: Determinants, Consequences, Accuracy, and Functional Significance. Annual review of psychology 66: 519-545.

Train, K. 2009. Discrete Choice Models with Simulation. Cambridge: Cambridge University Press.

Tsfati, Y., D. Markowitz Elfassi, and I. Waismel-Manor. 2010. Exploring the Association Between Israeli Legislators' Physical Attractiveness and Their Television News Coverage. International Journal of Press/Politics 15 (2): 175-192.

Waismel-Manor, I., and Y. Tsfati. 2011. Why Do Better-Looking Members of Congress Receive More Television Coverage? Political Communication 28 (4): 440-463.

Publisher's Note Springer Nature remains neutral with regard to jurisdictional claims in published maps and institutional affiliations. 